\title{
AS MÍDIAS SOCIAIS COMO FERRAMENTA DE SUPORTE NO DESENVOLVIMENTO DE PRODUTOS
}

[ Autor 1 ] Ana Cláudia Costa de Araújo (anaclaudiacostaaraujo@gmail.com), Departamento de Engenharia de Produção, Universidade Federal do Rio Grande do Norte.

[ Autor 2 ] Marcela Silva Cavalcanti Rosa (marcela.cavalcantir@gmail.com), Departamento de Engenharia de Produção, Universidade Federal do Rio Grande do Norte.

[ Autor 3 ] Técia de Lima Silva (anaclaudiacostaaraujo@gmail.com), Departamento de Engenharia de Produção, Universidade Federal do Rio Grande do Norte.

[ Autor 4 ] Lara Gabriele Ferreira de Medeiros (lara.gabriele@ gmail.com), Departamento de Engenharia de Produção, Universidade Federal do Rio Grande do Norte.

[ Autor 5 ] Mario Orestes Aguirre González (mario@ct.ufrn.br), Departamento de Engenharia de Produção, Universidade Federal do Rio Grande do Norte.

\section{RESUMO}

Para que a etapa de desenvolvimento do produto seja eficaz ela deve atender as necessidades de consumo do público-alvo através de uma interação com o usuário que se estrutura na colaboração. Sendo assim, o objeto deste estudo é conhecer qual a percepção dos consumidores quando empresas abrem seu processo de desenvolvimento do produto através das mídias sociais. Para responder essas questões, foram aplicados questionários estruturados online como instrumento de coleta de dados, exclusivamente a usuários de redes sociais. Obteve-se 341 respostas, tratadas através de estatística descritiva, onde foi possível identificar que a $89,1 \%$ das pessoas já utilizam as redes sociais para interagir com as empresas. Também observou-se que em sua minoria os respondentes buscam sugerir melhorias ou propostas de produto, em contrapartida, os resultados apontaram que o consumidor tem uma percepção positiva quanto ao relacionamento com a empresa após contribuir com o processo de desenvolvimento de produto e que essa interação permitiria melhorar ou criar produtos mais adequados às necessidades dos clientes. Dessa forma, o estudo identificou que a prática de utilizar mídias sociais no desenvolvimento de produtos pode ser aplicado como vantagem competitiva, por um lado, melhorando a interação entre empresa-cliente, por outro lado desenvolvendo produtos mais adequados aos reais desejos do seu público-alvo.

Palavras-chave: Mídias Sociais; Desenvolvimento de Produtos; Consumidores.

Área: Melhoria do processo de desenvolvimento de produtos e serviços

\section{INTRODUÇÃO}

A fase atual da sociedade - também conhecida por Era do Conhecimento - é caracterizada pela velocidade de informações, conhecimentos e desenvolvimento tecnológico (PFEIFFER, 2016). A principal ferramenta da Era do Conhecimento é a internet e, neste sentido, ela constitui a base que permite o funcionamento de diferentes plataformas de operações. Por sua vez, estas promovem a conexão entre as partes e, a partir disso, a realização de outras 
atividades com focos comunicacionais pré-determinados: compra e venda, interação social, informação, entre outros.

Juntamente com a evolução da internet, várias plataformas de interação social se sobressaíram, entre elas, as mídias sociais, que podem ser definidas como ferramentas para gerar conteúdo em tempo real e assim construir relacionamento na comunidade online (RODRIGUEZ et al. 2012).

As mídias sociais têm sido utilizadas estrategicamente pelas organizações, principalmente no que tange a sua relação direta com o consumidor. Através da percepção do consumidor é possível identificar requisitos para o desenvolvimento de um produto (PFEIFFER, 2016), ou ainda, através de plataformas de crowdsourcing é possível sugerir melhorias para um projeto de produto e financiar a sua construção. Nesta conjuntura, indagou-se sobre: "como o consumidor, presente nas mídias sociais, interfere na construção e desenvolvimento do produto?".

Desta forma, este estudo tem como objetivo conhecer qual o impacto sobre os consumidores quando empresas abrem seu processo de desenvolvimento do produto através das mídias sociais. De forma mais específica, o estudo ainda aborda quais mídias sociais são mais utilizadas pelo consumidor para entrar em contato com as empresas e qual é a intenção e percepções do consumidor com essa comunicação.

O artigo em questão é organizado pelas seguintes seções: esta introdução; em seguida o método de pesquisa; o referencial teórico que permeia os conceitos de mídias sociais, o papel do consumidor no desenvolvimento de produtos e o consumidor como parte de tal processo; no demais os resultados do estudo, as considerações finais e as referências bibliográficas.

\section{MÍDIAS SOCIAIS}

A evolução da internet propiciou o surgimento de plataformas inovadoras, tais quais as mídias sociais, cujo propósito é facilitar o processo de comunicação entre pessoas. O surgimento de tais ferramentas é consequência da evolução do comportamento humano. Atualmente, o mundo vive a era do Socialnomics, o termo descreve a economia na era das redes sociais digitais, em que os consumidores e as comunidades que eles criam online exercem uma influência profunda na economia e nos negócios que nela operam (GABRIEL, 2010). Assim, a mídia social é vista como uma abordagem econômica para agregar consumidores diferentes em um mesmo espaço, onde eles possam compartilhar seus conhecimentos e interesses (CONSTANTINIDES; FOUNTAIN, 2008).

De acordo com Chan-Olmsted et al. (2013), dentre as propriedades principais das mídias sociais pode-se citar: conversação, participação, formação de comunidades, fluxo de informações e conectividade. Sob esta ótica, essas ferramentas têm um papel importante em traduzir o perfil do consumidor para a empresa, visto que a informação gerada e acumulada nestas plataformas facilita o processo de identificação do público-alvo, além de melhorar a experiência de relacionamento do cliente com a marca (CHEN et al., 2009).

No que concerne estimular o usuário a contribuir com ideias e sugestões, a empresa/marca deve traçar estratégias adequadas para envolver o seu público-alvo e gerar valor, mediante as mídias sociais que participa. O desenvolvimento das estratégias dentro das mídias sociais não se conecta diretamente a tecnologia de fácil acesso, que atualmente está disponível a qualquer usuário, e sim está baseada em um conceito bem mais antigo, o de construir e solidificar relacionamento com clientes de modo que eles se sintam especiais ao ter um primeiro contato com a empresa/marca. 
É mediante essas plataformas que o usuário pode interagir de forma mais simples com a empresa/marca. Neste viés, as mídias sociais assumem o formato de SAC (Serviço de Atendimento ao Consumidor) dentro da web 2.0, que permite a criação e troca de informação gerada pelo consumidor (Kaplan e Haenlein, 2010). Segundo Ngai et al. (2015) o termo nasceu em 2004 por Tom O'Reilly para fazer referência a sites, em que as pessoas podem compartilhar, escrever e armazenar informações.

Dentre as mídias sociais onde o consumidor é mais ativo pode-se citar o Facebook e o Instagram., cada uma com configurações e formatos de conteúdo específicos. O Facebook foi criado em 2004 e pode ser utilizado para "networking", localizar oportunidades de negócios, método de comunicação entre empresas, plataforma para organizar e controlar eventos, bem como um meio para fornecer atualizações entre organizações e departamentos. Além disso, possui funções que auxiliam na promoção de um novo produto ou serviço (SAFKO; BRAKE, 2010).

Já o aplicativo Instagram foi lançado em 2010 e inicialmente apresentava como funções básicas a publicação de fotos, vídeos e comentários dos demais usuários. De acordo com o site do Instagram o crescimento exponencial ocorreu em 2014, quando a rede atingiu a marca de 300 milhões de usuários. Lessa (2015) afirma que a mídia social tem utilidade tanto para fins sociais, quanto para comerciais, visto que atualmente grandes empresas do mundo todo utilizam o Instagram para relacionar-se com os seus consumidores e assim promover os seus produtos ou serviços.

Diante disso, essas mídias sociais atuam como propulsoras do relacionamento entre marca/empresa. Essas plataformas apresentam funções essenciais para manter a marca mais próxima do público-alvo, e consequentemente contribuir na edificação de estratégias de marketing mais eficazes para o desenvolvimento de um produto ou serviço específico cada vez mais alinhado com o perfil do consumidor.

\section{O PAPEL DAS MÍDIAS NO DESENVOLVIMENTO DE PRODUTOS}

Nessa perspectiva, as mídias sociais podem se integrar com o Projeto de Desenvolvimento de Produtos (PDP) de diversas formas, seja através da pesquisa de satisfação do consumidor (PFEIFFER, 2016), pelas ferramentas de crowdfunding, associada a pesquisas de mercado tradicionais (CARR et. al, 2014) ou ainda utilizando-as para ter foco no consumidor (DU; YALCINKAYA; BSTIELER, 2016; MOUNT; MARTINEZ, 2014 ).

Segundo Pfeiffer (2016), o PDP e as mídias sociais se conectam por meio da satisfação do consumidor, que tem uma relevância semelhante ao marketing boca-a-boca e que, através da identificação dos desejos e necessidades do consumidor, permite que uma empresa defina as especificações do seu produto (Para esse estudo, Pfeiffer utilizou o método de Kano).

Outra maneira de integrar mídias sociais no PDP é na fase da ideação, fazendo uso das ferramentas de crowdsourcing. Por meio de ferramentas deste tipo os usuários podem sugerir novas ideias para produtos assim como opinar e votar em outras ideias, podendo inclusive ajudar a financiar os projetos de forma colaborativa (crowdfunding) - exemplo disso são a plataforma Kickstarter e o site Catarse.

Para Carr et. al (2014, p.365) "Nas mãos de pesquisadores qualitativos, as mídias sociais podem ser uma ferramenta eficiente para complementar a tradicional pesquisa qualitativa". Ou seja, as mídias sociais não são necessariamente o único caminho para identificar os requisitos PDP, mas associado às pesquisas de mercado tradicionais podem se tornar ainda mais relevantes, contanto que as empresas estejam atentas às mudanças ocorridas nas redes. 
Pode-se, então, associar a interação que ocorre entre os usuários com o desenvolvimento de novos produtos nas redes sociais como open innovation - inovação aberta. A inovação aberta pelos meios de comunicação social na forma de canais online, está crescendo rapidamente devido ao seu potencial para aproveitar o conhecimento diverso e promover a inovação entre uma rede mais ampla de usuários e parceiros (MOUNT; MARTINEZ, 2014).

As mídias sociais ainda podem ser uma importante ferramenta para o desenvolvimento com o foco no consumidor, uma vez que "Consumidores são o grupo stakeholder mais importante no desenvolvimento de novo produto e a oferta deste novo produto procura atender as necessidades dos consumidores em constante mudança." (DU; YALCINKAYA; BSTIELER, 2016, p.59). Pois, a internet proporciona um acesso extremamente rápido a informação e de constante mudança, o que permite uma melhor adaptação dos produtos aos interesses do consumidor.

\section{O CONSUMIDOR COMO PARTE DO PROCESSO}

As empresas estão cada vez mais empenhadas em coletar informações. De acordo com Franke et. al (2006), uma técnica alternativa para obter essas informações seria através da investigação do envolvimento e percepção de consumidores no processo de desenvolvimento de produtos. O estudo de González e Toledo (2012) reuniu diversas definições para a integração do cliente (IC) no PDP, relacionadas na Tabela 1 abaixo.

Tabela 1 - Definições para IC no PDP. Fonte: González e Toledo (2012)

\begin{tabular}{|c|c|}
\hline Autor & Definiçāo \\
\hline Kanlio (1998) & $\begin{array}{l}\text { A integraçâo do cliente consiste nas atividades de interaçâo entre os clientes e a equipe } \\
\text { de desenvolvimento de novos produtos. }\end{array}$ \\
\hline $\begin{array}{l}\text { Neale e Corkindale } \\
\qquad(1998)\end{array}$ & $\begin{array}{l}\text { Co-desenvolvimento é o processo pelo qual as empresas que desenvolvem o novo } \\
\text { produto e o cliente tomam-se intimamente envolvidos no desenvolvimento, } \\
\text { contribuindo com seus conhecimentos e experiências. De maneira geral, os clientes } \\
\text { fomecem conhecimentos para aplicaçâo do produto e o fabricante, o conhecimento } \\
\text { sobre a tecrologia do produto e processo. }\end{array}$ \\
\hline Ritter e Walter (2003) & $\begin{array}{l}\text { Refere-se à abrangência ou amplitude de participação de clientes no processo de } \\
\text { desenvolvimento de produto, desde a geração da ideia até o teste do protótipo. }\end{array}$ \\
\hline Kujala (2003) & $\begin{array}{l}\text { A IC pode ser entendida como um termo que descreve o contato direto entre os clientes } \\
\text { e a empresa fabricante durante o desenvolvimento do novo produto. }\end{array}$ \\
\hline Dahlsten (2004) & $\begin{array}{l}\text { A IC no PDP pode ser definida como um processo de socialização no qual o } \\
\text { conhecimento tácito do cliente é obtido pela empresa. }\end{array}$ \\
\hline $\begin{array}{l}\text { Kristensson, } \\
\text { Gustafason e Archer } \\
\text { (2004) }\end{array}$ & $\begin{array}{l}\text { A IC no PDP oferece uma nova abordagem para sumentar a satisfaçào dos clientes pelo } \\
\text { atendimento de suas necessidades explícitas e implicitas. }\end{array}$ \\
\hline $\begin{array}{l}\text { Enkel, Kausch e } \\
\text { Gasamann }(2005) \text { e } \\
\text { Gasamann e Wecht } \\
\text { (2005) }\end{array}$ & $\begin{array}{c}\text { A IC no PDP é um método, cada vez mais aplicado, que objetiva reduzir o riaco de } \\
\text { falha do produto no seu lançamento no mercado. }\end{array}$ \\
\hline $\begin{array}{l}\text { Gasamann, Sandmeia } \\
\text { e Wecht }(2006)\end{array}$ & $\begin{array}{l}\text { A IC é definida como a integraça de clientes, clientes dos clientes ou intermediários } \\
\text { de clientes nas fases iniciais do processo de desenvolvimento de novos produtos, } \\
\text { caracterizada pela participaçào ativa dos clientes. }\end{array}$ \\
\hline $\mathrm{Pals}$ et al. (2008) & $\begin{array}{l}\text { A IC nào significa pesquisar as necessidades dos clientes e criar um produto para eles, } \\
\text { mas, sim, a aprendizagem mútua entre a empresa fabricante e os clientes no PDP. }\end{array}$ \\
\hline
\end{tabular}


Neste processo de envolvimento do cliente no PDP diversas vantagens para a organização se sobressaem. González e Toledo (2012) reuniu os benefícios potenciais em seu trabalho, sendo eles as ideias para inovação radical e incremental, a redução de incertezas e riscos de novos produtos, a redução do custo de desenvolvimento e do número de mudanças do projeto, o aumento do nível de parceria e da produtividade da equipe.

O desenvolvimento dos consumidores no PDP pode se fazer por meio de diferentes mecanismos. O trabalho de Santos e Brasil (2010) analisou empresas brasileiras de bens de consumo e encontrou os mecanismos mais utilizados. Seriam estes: recebimento de telefonemas, faxes, e-mails e cartas com sugestões de novos produtos; grupos focais; teste de conceito; teste de produto; visitas e reuniões dos consumidores com a equipe de desenvolvimento de produtos; observação de consumidores; comunidades virtuais (fóruns de discussão na internet) e ferramentas virtuais que permitem a usuários criar design e novas funcionalidades. Destes, os resultados do estudo ainda apontaram que os mais utilizados foram os canais mais passivos e tradicionais, como o telefone e o e-mail.

Vale ressaltar ainda que os consumidores podem estar envolvidos com o PDP em diferentes graus de intensidade. A pesquisa de Santos e Brasil (2010) também se destinou a investigar essa intensidade do envolvimento dos clientes, descrita na Tabela abaixo.

Tabela 2 - Intensidade do envolvimento do cliente no processo do PDP. Fonte: Adaptado de Santos e Brasil (2010)

\begin{tabular}{|c|c|c|c|}
\hline & Baixa intensidade & Moderada intensidade & Alta intensidade \\
\hline $\begin{array}{l}\text { Estágio em que } \\
\text { o cliente se } \\
\text { envolve }\end{array}$ & $\begin{array}{l}\text { Estágio de } \\
\text { comercializaçâo }\end{array}$ & $\begin{array}{c}\text { Estágios de geração de } \\
\text { ideias, análise da ideia e } \\
\text { teste de produto }\end{array}$ & $\begin{array}{l}\text { Estágio de desenvolvimento, junto a } \\
\text { fomecedores e outros atores }\end{array}$ \\
\hline $\begin{array}{l}\text { Como se dá a } \\
\text { geraçăo de } \\
\text { ideias }\end{array}$ & $\begin{array}{l}\text { Pesquisa em outros } \\
\text { mercados e em empresas } \\
\text { concorrentes }\end{array}$ & $\begin{array}{l}\text { Técnicas tradicionais de } \\
\text { pesquisa de marketing, } \\
\text { como grupos focais e } \\
\text { observaçōes. }\end{array}$ & $\begin{array}{l}\text { Desde técricas tradicionais de } \\
\text { pesquisa de marketing até reuniōes } \\
\text { com grupos de consumidores e } \\
\text { ferramentas virtuais de interaçầo }\end{array}$ \\
\hline $\begin{array}{l}\text { Como a } \\
\text { empresa se } \\
\text { comunica com } \\
\text { o cliente }\end{array}$ & $\begin{array}{l}\text { Forma unilateral, partindo } \\
\text { da empresa e chegando } \\
\text { até aos consumidores. }\end{array}$ & $\begin{array}{l}\text { Nâo é reconhecida pelo } \\
\text { diálogo, ocomendo de } \\
\text { forma unilateral. }\end{array}$ & $\begin{array}{c}\text { Bidirecional, consumidores e } \\
\text { representantes das empresas } \\
\text { dialogam. }\end{array}$ \\
\hline
\end{tabular}

Pode-se observar que quanto mais envolvido o cliente se encontra no processo de PDP, mais ampla é a variedade de mecanismos utilizados neste processo. Também a comunicação se mostrou mais abrangente, assim como o relacionamento com outros envolvidos no processo. Os investimentos também aumentam consoante com o grau de envolvimento. É necessário também destacar a mudança que vem acontecendo neste processo de envolvimento em que o consumidor faz parte. Para Moller et al (2008) as novas ferramentas tecnológicas, como a internet, que apresenta recursos de interação a baixo custo para a empresa, estão entre dos principais fatos que merecem destaque.

Da percepção do cliente, também vantagens são apresentadas quando a internet, em especial as redes sociais, são utilizadas como mecanismos de envolvimento do consumidor no PDP. Cada vez mais conectados, é de grande conveniência e familiaridade para os consumidores o uso deste tipo de interação. 
Como exemplo disso, tem-se o projeto de criação do automóvel Fiat mio, que utilizou a plataforma de internet para incentivar a geração de ideias e coletá-las a fim de lançar no mercado um carro criado inteiramente por meio de ideias dos consumidores. Entre os resultados deste projeto, tem-se um número de mais de 10000 ideias, vindas de mais de 17000 participantes, que continuam a surgir mesmo depois do lançamento do automóvel, em 2010.

Costa (2013) estudou o projeto de co-criação do Fiat Mio da perspectiva do consumidor e como resultado de seu trabalho obteve uma vasta lista de sentimentos, indicando a riqueza da dimensão afetiva que a experiência de um projeto colaborativo entre empresa e consumidor é capaz de gerar. A percepção dos consumidores trouxe à tona o sentimento de reconhecimento, proporcional à interação que a empresa realiza com ele, gerando motivação para continuidade de sua participação. Quanto ao fator tempo, que antes era um impeditivo para o cliente, o autor também identificou uma vantagem: o uso das plataformas móveis agilizam o processo.

São, então, muitos os fatores a serem considerados no envolvimento do cliente com o PDP. O mecanismo que se utiliza, a intensidade que se dá essa relação, a fase em que isto ocorre, os benefícios que podem gerar para ambas as partes e os fatores impeditivos. Todos estes fatores atuam de forma conjunta na busca pela transformação do papel do cliente de espectador passivo para participante ativo e, portanto, necessitam de bastante atenção por parte das organizações que almejem criar valor para seus clientes através do desenvolvimento de novos produtos.

\section{MÉTODO}

Esta pesquisa consiste em uma revisão exploratória da literatura acerca dos temas de mídias sociais, desenvolvimento de produtos e a percepção e envolvimento do consumidor neste processo. Para verificar tal referencial na prática, foi realizada uma pesquisa do tipo survey visando descobrir o perfil deste consumidor. O survey foi hospedado em uma plataforma online e divulgado por meio de um mailing direcionado a membros de um grupo de pesquisa da cidade de Natal/RN, bem como por redes sociais (Facebook e WhatsApp). O questionário foi desenvolvido embasando-se no trabalho de Costa (2013), contém 10 perguntas objetivas e foi aplicado durante dois dias, reunindo 341 respondentes. Este pode ser visualizado no link a seguir: https://goo.gl/forms/B6rhlCWnlNrvp21F2 . O resultado foi analisado com estatística descritiva e demonstra a contribuição da pesquisa ao detalhar o perfil do consumidor disposto a relacionar-se mais ativamente com as empresas em relação ao desenvolvimento de produtos.

\section{RESULTADOS}

A partir das 341 respostas obtidas com a aplicação do survey foi possível captar o entendimento dos respondentes em relação à integração do cliente com o processo de desenvolvimento de produtos (PDP) de uma empresa tendo como suporte as mídias sociais.

O grupo de pesquisa, composto por uma maioria de mulheres entre 18 e 26 anos, replicou o questionário em suas redes sociais. Desta forma, os participantes da pesquisa foram solicitados a responder como se dá atualmente seu relacionamento com as empresas através de mídias sociais, além de fornecer sua percepção quanto aos benefícios e fatores motivacionais para participar do desenvolvimento de um produto. Também por meio das 10 questões fechadas, tornou-se possível identificar o tipo de consumidor potencial, bem como as redes sociais mais propícias a este tipo de relacionamento. 
No que concerne o número de pessoas que já utilizam redes sociais para interagir com perfis de empresas, atingiu-se um resultado positivo de $89,1 \%$. Pode-se traduzir este número como um contexto inicial favorável ao desenvolvimento de produtos via mídias sociais, uma vez que este relacionamento consumidor-empresa já está estabelecido neste meio.

Quanto ao perfil dos consumidores, a amostra geral desta pesquisa contou com maioria de mulheres (59.2\%) entre 18 e 25 anos (60.4\%). A mesma majoritariedade pode ser percebida nos que afirmaram utilizar redes sociais para interagir com a empresa, uma vez que obteve-se uma maioria de mulheres $(61,18 \%)$ de 18 a 25 anos $(38,49 \%)$. Esta informação é relevante na medida em que revela o gênero e a faixa etária que mais estão favoráveis a participar de um PDP via redes sociais.

Em relação às plataformas de contato, observou-se que o Facebook e o Instagram foram as plataformas apontadas com maior potencial e mais utilizadas como meio para interação consumidor-empresa, com $72,7 \%$ e $62,5 \%$ respectivamente, dentre as outras opções apresentadas como o Twitter, site da própria empresa, Whatsapp, e-mail, telefone, Linkedin ou sites de reclamações e avaliações.

Vale ainda ressaltar que apesar de já existir uma interação cliente-empresa pelas mídias sociais, a maioria dos respondentes $(67.1 \%)$ interage com o propósito de tirar dúvidas. Em oposição, questões mais relacionadas com o desenvolvimento de produtos, como sugestão de melhorias ou proposta de novos serviços/produtos foram os objetivos que menos receberam a atenção do consumidor ao entrar em contato com a empresa pela mídia social, com 3,9\% e $0,6 \%$ dos respondentes, respectivamente.

Neste sentido, vale ainda ressaltar a interação do consumidor com o propósito de realizar uma crítica sobre o produto/serviço. Esta se revelou potencial para o desenvolvimento de novos produtos, uma vez que foi a segunda forma de interação mais realizada pelos respondentes $(24.6 \%)$.

Outro cenário local desfavorável relaciona-se ao retorno que as empresas dão aos consumidores pelas plataformas online. Apesar de 89,1\% dos respondentes procurarem um relacionamento com a empresa por meio das redes sociais, apenas $35,52 \%$ destes consumidores informaram receber o retorno da empresa. Este quadro evidencia um cenário em que os consumidores estão dispostos e interessados neste tipo de relacionamento, mas as empresas ainda apresentam um despreparo para lidar com seus consumidores por meio das mídias sociais, enunciando uma necessidade de maior concentração de esforços.

Quando abordados especificamente sobre utilizar as mídias sociais como ferramenta de suporte no desenvolvimento de produtos, 49,6\% dos consumidores afirmaram que seriam motivados a dar ideias por estarem contribuindo para a sociedade. O segundo maior grupo, de $34,9 \%$ dos respondentes, declarou que a motivação se daria por meio de algum tipo de gratificação.

Os resultados deste estudo apontaram ainda que o consumidor possui uma percepção bastante positiva quanto ao relacionamento com a empresa após a interação. Numa escala de 0 a 10 , onde o número 0 significa um distanciamento da empresa, 5 era atribuído como relação neutra e 10 como máxima aproximação, $90,02 \%$ dos participantes desta pesquisa consideraram que o seu relacionamento com a empresa melhoraria após participarem com ideias no desenvolvimento de novos produtos (atribuindo notas de 6 a 10, com a maioria na nota 8). 
Por fim, captando o entendimento quanto aos benefícios para a empresa com a participação dos clientes com ideias para novos produtos, 73,3\% dos respondentes consideraram que um produto adequado às necessidades dos clientes é o maior dos benefícios, dentre os outros como maior rapidez no desenvolvimento de produtos, fidelização de clientes e cliente como meio de divulgação do produto.

\section{CONSIDERAÇÕES FINAIS}

A partir das informações apresentadas e do survey aplicado foi possível inferir a potencial relevância que o envolvimento do consumidor no processo de desenvolvimento de produtos traz para as empresas, bem como o papel aproximador das mídias sociais nesse cenário. Uma vez que as mídias fazem parte do dia-a-dia do consumidor elas se tornam um elemento de aproximação entre as empresas e seus clientes, permitindo um contato mais pessoal e humano.

O resultado obtido com o survey revelou dados cruciais para o entendimento da questão, especialmente no que concerne o cenário potiguar. As descobertas incluem: o perfil ideal do consumidor propenso a interagir espontaneamente com as empresas; as redes sociais mais interessantes para absorver o investimento das empresas; a intenção principal do consumidor para iniciar este contato virtual; a falha das empresas na manutenção deste relacionamento com o consumidor - e o espaço para melhoria; a abertura do mercado em participar de ações de relacionamento para oferecer input direcionado para as empresas; os principais incentivos capazes de motivar tal participação; o estreitamento do relacionamento entre cliente-empresa que tal envolvimento poderia trazer; e, por fim, a percepção do cliente sobre os benefícios que a empresa pode obter com esta iniciativa.

Logo, este artigo não apenas responde ao seu problema inicial de pesquisa, que se propôs a identificar a percepção do consumidor sobre o PDP utilizando as redes sociais, como aprofunda a questão, mapeando elementos-chave para a futura inserção de empresas nesta prática de mercado. Este estudo identificou, ainda, que a prática de utilizar mídias sociais no desenvolvimento de produtos pode ser usada como vantagem competitiva para as organizações, melhorando a interação entre empresa-cliente ao mesmo tempo em que desenvolve produtos mais adequados aos reais desejos do seu público-alvo. Isto se dá pois para a empresa o investimento é relativamente baixo em face de um retorno considerável.

O presente estudo ainda apresenta algumas limitações. Como a réplica do questionário se deu através de mídias sociais de pessoas com o perfil semelhante, a possibilidade de reunir respondentes que compartilhem deste mesmo perfil e interesses limita a amostra da atual pesquisa. Desta forma, como apontamento para futuros estudos, recomenda-se a aplicação do questionário em uma amostra mais diversificada e a validação com especialistas da área.

\section{REFERÊNCIAS}

CARR, J.; DECRETON, L.; QIN, W.; ROJAS, B.; ROSSOCHACKI, T.; YANG, Y. Social media in product development. Food Quality And Preference, Nova Iorque, v. 40, pp. 354364, 2014. Disponível em: <http://www.sciencedirect.com/science/article/pii/S0950329314000585>. Acesso em: 2 maio 2017.

CHAN-OLMSTED, S.M.; CHO, M.; LEE, S. User perceptions of social media: a comparative study of perceived characteristics and user profiles by social media. Online Journal of Communication and Media Technologies, v.3, pp. 149-178, 2013. 
CHEN, L.; GOES, P.; MARSDEN, J.R.; ZHANG, Z. Design and use of preference markets for evaluation of early stage technologies. Journal of Management Information Systems, v. 26, pp. 45-70, 2009.

CONSTANTINIDES, E.; FOUNTAIN, S. Web 2.0: conceptual foundations and marketing issues. Journal of Direct, Data and Digital Marketing Practice. v. 9, pp. 231-244, 2008.

COSTA, D. F. Co-criação: uma perspectiva do consumidor. Dissertação de mestrado.

Faculdade de Administração e Contabilidade de Ribeirão Preto: USP: Ribeirão Preto, 2013, $162 \mathrm{p}$.

DU, S; YALCINKAYA, G; BSTIELER, L. Sustainability, Social Media Driven Open Innovation, and New Product Development Performance. Journal of product innovation management, v. 33, pp. 55-71, 17 nov. 2016. Disponível em:

<http://dx.doi.org/10.1111/jpim.12334>. Acesso em: 2 maio 2017.

FRANKE, N; VON HIPPEL, E; SCHREIER, M. Finding commercially attractive user innovations: a test of lead-user theory. The Journal of Product Innovation Management, v. 23, n. 4, p. 301-315, 2006.

GABRIEL, M. O marketing na era digital: conceitos, plataformas e estratégias. São Paulo: Novatec, 2010.

GONZÁLEZ, M. O. A \& TOLEDO, J.C. A integração do cliente no processo de desenvolvimento de produto: revisão bibliográfica sistemática e temas para pesquisa. Produção, v. 22, n. 1, p. 14-26, jan./fev. 2012.

KAPLAN, A. M.; HAENLEIN, M. Users of the world, unite! The challenges and opportunities of social media. Business Horizons. v. 53, pp. 29-68, 2010.

LESSA, R. Os segredos do Instagram. Digitalcoaching. Disponível em: $<$ http://pt.slideshare.net/DigitalCoaching/os-segredos-do-instagram?qid=ff21af71-aca5-44e2b7e1-d898cdd5fa34\&v=default\&b=\&from_search=5>. Acesso em: 23 maio 2017.

MÖLLER, K.; RAJALA, R.; WESTERLUND, M. Service Innovation Myopia? A New Recipe for Client-Provider Value Creation. California Management Review, v. 50, n. 3. pp. 31-48, 2008.

MOUNT, M. P.; MARTINEZ, M. G. Social media: A tool for open innovation. California Management Review, California, n. 4, v. 56 , p.124-143, set. 2014. Disponível em: <https://www.researchgate.net/publication/266642620_Social_Media_A_Tool_for_Open_Inn ovation>. Acesso em: 2 maio 2017.

NGAI, E.W. T.; MOON, K. K.; LAM, S. S.; CHIN, E. S. K. Social media models, technologies, and applications an academic review and case study. Industrial Management \& Data Systems. v. 115, 2015.

PFEIFFER, P. Uso estratégico de mídias sociais no desenvolvimento de novos produtos: uma proposição de análise com o uso do modelo de Kano. 2016. 93 f. TCC (Graduação) - Curso de Administração, Departamento de Ciências da Administração, Universidade Federal de Santa Catarina, Florianópolis, 2016. Cap. 5. Disponível em: <https://repositorio.ufsc.br/handle/123456789/171259>. Acesso em: 2 maio 2017.

SAFKO, L.; BRAKE, D. A bíblia da mídia social: táticas, ferramentas e estratégias para construir e transformar negócios. Tradução de James Gama. $1^{\text {a }}$ Ed. São Paulo: Blucher, 2010. 
SANTOS, C. R.; BRASIL, V. S. Envolvimento do consumidor em processos de desenvolvimento de produtos: um estudo qualitativo junto a empresas de bens de consumo. Rev. adm. Empres, v.50, n.3, pp.300-311, 2010. 